\title{
Differentiated Instruction and Improving Student Learning: A Qualitative Study
}

\author{
Kasandra Alansa Scott ${ }^{1}$, Chris Cale ${ }^{1,2}$, Sunddip Panesar-Aguilar ${ }^{3,}$, Michelle McCraney $^{1}$ \\ ${ }^{1}$ Riley College of Education, Walden University, Minneapolis, USA \\ ${ }^{2}$ School of Education, Northcentral University, La Jolla, USA \\ ${ }^{3}$ School of Education, University of St. Augustine for Health Sciences, St. Augustine, USA
}

Email address:

saguilar@usa.edu (S. Panesar-Aguilar)

${ }^{*}$ Corresponding author

To cite this article:

Kasandra Alansa Scott, Chris Cale, Sunddip Panesar-Aguilar, Michelle McCraney. Differentiated Instruction and Improving Student Learning: A Qualitative Study. Education Journal. Vol. 10, No. 4, 2021, pp. 114-118. doi: 10.11648/j.edu.20211004.11

Received: June 19, 2021; Accepted: June 29, 2021; Published: July 5, 2021

\begin{abstract}
Administration and ministers of elementary schools located in the target district in the Caribbean reported that some elementary teachers were inconsistently implementing differentiated instruction (DI) in their practice. Based on the identified problem, it was unclear which specific strategies of DI were causing teachers to experience barriers or challenges during the process of implementation. The purpose of this basic qualitative study was to explore teacher perceptions in one district about their implementation of the conceptual framework, Weimer's learner-centered teaching theory DI model, in their classroom instruction. Data from schools in one elementary school district in the Beach School District were collected through virtual interviews with 15 teacher participants who had 5 to 10 years of teaching experience for Grades 5 to 6 . Data were analyzed with open coding using the RADaR model of analysis. Results indicated that, when teachers use limited and repetitive DI strategies, their use of the DI model in their practice is inconsistent. In addition, teachers indicated they would benefit from some additional training on alternative DI strategies as well as how to effectively differentiate their instruction consistently. The results of this research may contribute to positive social change by providing classroom teachers with additional resources and training to improve the implementation of DI in the classroom and enhance the learning experiences of students.
\end{abstract}

Keywords: Differentiated Instruction, Student Learning, Learner-centered Strategies, Classroom Teaching, Educational Practice

\section{Introduction}

The problem was that some elementary school teachers were inconsistently using differentiated instruction (DI) as based on Weimer's learner centered teaching theory (LCTT). At the study site, all elementary teachers are expected to differentiate their instruction and cater to their lessons with the learner at the center in Weimer's LCTT model. According to the Education Data Report, the California Achievement Test (CAT) assessments predicted that by the end of Grade 6, 79\% of students should achieve a Level 4 or higher in English and $76 \%$ of students should achieve a Level 4 in mathematics. [1-2] However, results from the latest CAT test depicted actual gains in English as 63\%, 16\% lower than predicted, and $48 \%$ in mathematics, $28 \%$ lower. This data illustrates that the
Grade 6 students are underachieving relative to the CAT estimates, illustrating a shallow level of learning and ineffective strategies used through teacher instruction. [2] Based on communication that occurred in staff meetings and recorded in meeting minutes, it has been stated that most of the teachers in the elementary schools are inconsistently using differentiated instructional methods, which signals a lack of catering to all students' learning needs. The problem addressed in this study was elementary teachers' inconsistent use of Weimer's LCTT differentiated instructional model in Grade 6 classrooms at the Beach School District. [1] Michael et al. reported in their research that teachers' instructional methods play a significant role in improving learning and that DI, among these methods, uniquely supports both high-ability students and those with a disability. [3] DI provides students with options and means where they can take on more of the 
responsibility for their own learning. Goh, Hannon, Webster, and Podlog reported in their research that some students fail to tie knowledge and skills taught through instructional methods such as DI. [4] Recent literature reports the challenges faced by teachers as they attempt to employ DI through the exploration of their perceptions of the method of differentiation. [5-6] An analysis of local school site data suggests that some teachers in the district elementary schools are using DI inconsistently. [7]

The inconsistent use of the model of DI has been proven to negatively impact learning for all students, as indicated in the literature review. [5-6] When the LCTT is combined with DI, all students including the gifted, those with disabilities, ELL and ESL students, increases are observed in their achievement and motivation for learning. Some studies have indicated that teacher perception of the model of DI plays a role in impacting their use and implementation in the classroom. [5-6] Researchers also indicated that teachers may need additional support, such as training educators on strategies they can use to consistently implement DI in the classroom. [5-6] The problem at the elementary schools in Beach School District was the inconsistent use of Weimer's LCTT differentiated instructional model in their teaching practice. [1]

\section{Methodology}

\subsection{Research Questions}

For this study, the following research question was used to discover the reason behind the inconsistent use of the model by elementary teachers:

RQ: What are teachers' perceptions about why they are inconsistently implementing Weimer's differentiated instructional model?

\subsection{Conceptual Framework}

This basic qualitative study was grounded in the conceptual framework of Weimer's learner-centered teaching theory (LCTT) of DI. [1] Weimer's theory focused on the learner and their development rather than the transmission of content. This model addressed the balance of power in the process of teaching and learning, where the teacher becomes a facilitator. The learner is viewed as an active agent who brings their knowledge, experience, education, and ideas to the learning process, which plays an integral role in their ability to take in new information and learn. [1]

The LCTT was initially introduced by Jean Jacque Rousseau in the mid-1700s based on his perception that educators should begin their instruction with the student's capability and interest in learning. [3] Weimer built upon Rousseau's theory by emphasizing that students' learning process becomes more meaningful when they are given the power to select topics that are interesting to them. Placing students at the center of the learning process, as the LCTT model suggests, gives students the platform to control their learning, and through this process, students become more engaged, and they develop problem-solving and critical thinking skills. [8]

The LCTT model by Weimer was selected for this study because this study was focused on the need to identify the reasons why teachers are inconsistently implementing Weimer's LCTT differentiated model. [1] In this study, the LCTT framework also assisted in the data analysis concerning teacher's inconsistent use of DI in the classroom. Weimer's LCTT framework is related to a qualitative approach due to the in-depth data that is generated during data collection. The LCTT framework served to guide the process of data collection and analysis to explain and validate how teacher perceptions of the DI model impact their implementation and use of DI in their daily instruction. The LCTT model was connected to the selected data collection instruments and procedures of data analysis. The created interview questions and researcher journal protocol are in alignment with the framework and intent of this study. The design of each data collection instruction assisted in highlighting the specific challenges and concerns that affect teachers' inconsistent use of Weimer's LCTT differentiated instructional model. The five features of Weimer's LCTT differentiated instructional model provided a framework from which to explore the study's problem and purpose. [1] Weimer's LCTT conceptual framework was relevant to this qualitative study as it provides valuable information and strategies that may assist teachers with differentiated instructional methods in the classroom. The research question in this study focused on identifying why Grade 6 elementary teachers are inconsistently using DI. Answering the research question will reveal if Grade 6 elementary teachers and their students' perceptions of DI determine the model's success and effectiveness in assisting students with becoming independent learners. In today's classrooms, the learning process of students is influenced by differences in their culture, language spoken, background, level of education, learning ability, readiness, and interest. For teachers to ensure learning, students must be appropriately challenged. [3] Challenges that seem too difficult or that fail to stimulate the learner will cause students to give up due to frustration, lack of motivation, or boredom. When teachers reflect on their practice, they can take into consideration that each student learns differently, which means that their instruction or practice must reflect catering to their students' needs. DI is an integral asset to educational systems worldwide because this model provides specialized teaching that better meets students' various learning needs. [3, 8]

\subsubsection{Research Design Appropriateness}

To address the study problem, a basic qualitative study methodology was utilized. This model allows for a researcher to take an in-depth look at a small group of subjects, thereby narrowing the field of research. In the basic qualitative study approach, data was collected via different sources for compiled analysis. Due to the nature of the inquiry and the small number of participants involved, a basic qualitative study was a strong choice because it yields the most useful data with a small sample size. The basic qualitative study approach was suitable for my research as it provided me with 
the ability to gather valid data from participants' responses and perspectives through virtual interviews. [9]

\subsubsection{Participant Selection}

Participants for this basic qualitative study were from two elementary schools in the Beach School District of the study site, which educates students in kindergarten to Grade 6 . There are currently eighteen teachers, two deputy principals, two principals, an educational psychologist, a music teacher, an art teacher, a P. E. teacher, and two secretaries across both schools. The teaching staff at the Beach School District elementary schools is made up of two men and 24 females. Approximately $85 \%$ of the teaching staff have 10 or more years of teaching experience, whereas two teachers have 5 to 7 years of teaching experience.

\subsubsection{Sampling}

A purposeful sample was used to select a total of 15 teachers from a pool of 24 teachers at the study site to participate in the study on the basis that this group of teachers were knowledgeable about or had experience with the phenomenon of interest. Elementary teachers who were eligible to participate and who met the following criteria were selected as potential participants for the study. Each chosen participant needed to be (a) a full-time teacher at the elementary level, (b) have 5 to 10 years of teaching experience, (c) teach Grades 5 or 6, and (d) have knowledge of Weimer's LCTT differentiated instructional model. [1]

\section{Data Collection and Analysis}

\subsection{Interviews}

Virtual interviews were conducted with each of the 15 teacher participants to gather their perceptions about implementing Weimer's LCTT differentiated instructional model in their classroom and teaching practice. [1] An open-ended protocol was used to generate additional questions that further probed the participants for more information and insights into the study. A researcher journal was also used to record and reflect on all that has been observed on a phenomenon being studied. [10] Researcher journals are also used for improving the reliability of research. The data collected from the virtual interviews helped understand the findings regarding teachers' perceptions about their implementation of Weimer's LCTT differentiated instructional model in their classroom instruction. The researcher journal as a secondary data source helped to keep a personal record of the process, key decisions, and feelings during the study, and offered the opportunity to learn from the research process. [11]

\subsection{Data Analysis and Findings}

Data collected from the virtual interviews was analyzed first by in vivo coding, which is the practice of assigning a label to a section of data, such as an interview transcription, using a simple word, phrase, or sentence that is highlighted as significant from the segment of text. [10-11] In vivo coding was used to review the written interview transcripts to highlight: common ideas, themes, and patterns expressed by the teacher participants. Active learning, cooperative learning, inductive teaching, and learning from the LCTT framework served as the selected predetermined codes for the narrative analysis of the data, as they are essential components of the LCTT framework and are important for teachers to effectively implement DI in their classroom and teaching practice. [8] The highlighted words, phrases, and themes were recorded in a table. Afterward, the generated list to identify key categories was analyzed. QDA Miner Lite, a computer-assisted qualitative analysis software, was used to accurately analyze the textured data of the virtual interview scripts and researcher journal. During the interviews, each participant was provided with a printed interview script, which they reviewed to check to use member checking to verify that the themes are accurately represented. Two data checks in the form member checks and a researcher journal to test the validity of the data and triangulation was used. Each set of collected data was scrutinized so that the researchers can find evidence to support each theme identified. [12] Once the evidence had been found, the data was then deemed accurate.

The five steps of the RADar technique were completed three times to discover the themes. The main themes that emerged from the research question were: (a) lack of planning time, (b) mental challenges of differentiating every lesson, (c) mixed abilities and learning in need of effective accommodation, (d) lack of assistance or support in the classroom, (e) lack of parental support, (f) hands-on resources limiting special needs students' progress and distracting them and negatively impacting their behavior, and (g) lack of differentiation in standardized tests (see Table 1).

Table 1. Table information.

\begin{tabular}{ll}
\hline Research Question & Theme \\
\hline & 1. Lack on planning time. \\
What are teachers' & 2. Mental challenges of differentiating of every lesson \\
perceptions about why they & 3. Mixed abilities and learning in need of effective accommodation. \\
are inconsistently & 4. Lack of assistance or support in the class- room. \\
implementing Weimer's & 5. Lack of parental support. \\
differentiated instruction & 6. Hands on resources limiting special needs students' progress and distracting them and negatively impacting behaviour. \\
model? & 7. Lack of differentiation in standardized tests. \\
\hline
\end{tabular}




\section{Conclusion}

The purpose of this qualitative study was to explore teacher perceptions in Beach School District at the study site about their implementation of Weimer's differentiated instructional model. Although all 15 teacher participants mentioned having some knowledge of DI strategies that they use in the classroom, their responses indicating awareness of DI strategies were limited to basic strategies, and they did not have specific training in DI and learner-centered strategies. Effective PD enables teachers to develop the knowledge and skills necessary to address students' learning challenges.

The findings of this study reveal possible limitations. The first limitation was that the sample size or selection of participants was rather small to produce valid or precise results, making it difficult to identify significant relationships from the data. [13] Another limitation of this study was that the pool of participants had to be expanded to lower grade levels other than Grades 5 and 6 to get the 15 participants. A third limitation was the method of data collection. For this study, virtual interviews were conducted to gather information due to the COVID-19 pandemic and school closures, limiting thorough analyses of results. [14]

In this study, the identified problem was that some elementary teachers were inconsistently using DI as based on Weimer's LCTT. Data collected via virtual interviews using Microsoft Teams due to school closures during the COVID-19 pandemic occurred. Alternately, a mixed methods approach that would have allowed the opportunity to use an additional data collection method or instrument such as a survey for the teacher participants. The use of a survey could have provided additional insights into the study's problem and aided with more valid and precise results. In addition, the use of a survey could have provided crucial information on the participants' knowledge of Weimer's LCTT, DI, and how they determine which strategies to use to meet their students' needs. Surveys can increase and expand sample sizes to produce more valid data. The participant pool could also have been expanded to neighboring districts making relationships between the collected data easier to identify and analyze.

The LCTT fosters learning in communication with teachers and other learners; taking students seriously as active participants in their learning and fosters transferable skills such as problem-solving, critical thinking, and reflective thinking. [4-6] DI allows teachers to manage what students learn, how students learn, and how students are assessed. With flexibility, DI allows teachers to maximize individual growth in the course content. [8] Therefore, it is essential that teachers at the elementary level consistently implement DI and learner-centered strategies to meet students' needs and help them develop into independent learners. The findings from analyses of collected data revealed that while teachers at the study site were using some DI strategies, their knowledge of DI and learner-centered strategies was limited and could be strengthened. The conducted interviews helped to gain an understanding of the participants' knowledge of the LCTT and model of DI and how this knowledge affects their consistent implementation. Improved teacher instruction in DI and learner-centered strategies, may impact students' independent learning experiences as their specific learning needs are met and this may transfer beyond their elementary learning to tertiary education.

\section{References}

[1] Weimer, M. (2002). Learner-centered teaching: Five key changes to practice. San Francisco: John Wiley \& Sons, pp. xvi-xix, 125.

[2] Ministry of Education. (2017). Education data report. [Data file].

http://www.education.gob.ky/portal/pls/portal/docs/1/1272512 7.PDF

[3] Michael, R. D., Webster, C. A., Egan, C. A., Stewart, G., Nilges, L., Brian, A., Johnson, R., Carson, R., Orendorff, K. \& Vazou, S. (2018). Viability of university service learning to support movement integration in elementary classrooms: Perspectives of teachers, university students, and course instructors. Teaching and Teacher Education, 72, 122-132. https://doi.org/10.1016/j.tate.2018.03.003

[4] Goh, T. L., Hannon, J. C., Webster, C. A., \& Podlog, L. (2017). Classroom teachers' experiences implementing a movement integration program: Barriers, facilitators, and continuance. Teaching and Teacher Education, 66, 88-95. https://doi.org10.1016/j.tate.2017.04.003

[5] Andrietti, V., \& Su, X. (2019). Education curriculum and student achievement: theory and evidence. Education Economics, 27 (1), 4-19. https://doi.org/10.1080/09645292.2018.1527894

[6] Guay, F., \& Bureau, J. S. (2018). Motivation at school: Differentiation between and within school subjects matters in the prediction of academic achievement. Contemporary Educational Psychology, 54, 42-54. https://doi.org/10.1016/j.cedpsych.2018.05.004

[7] Office of Education Standards. (2019). School inspection reports 2018-2019. [Data file]. http://www.gov.ky/portal/page/portal/esahome/publications/S chool\%20Inspection\%20Rports\%2020192020/Full\%20Inspec tion\%20Report $\% 20$ Creek\%20and $\% 20$ Spot $\% 20$ Bay\%20Prima ry\%20School\%202019.

[8] Gilboy, M. B., Heinerichs, S., \& Pazzaglia, G. (2015). Enhancing student engagement using the flipped classroom. Journal of Nutrition Education and Behavior, 47 (1), 109-114. https://doi.org/10.1016/j.jneb.2014.08.008

[9] Brooks, J. S., \& Normore, A. H. (2018). Qualitative research in educational leadership studies: Issues in the design and conduct of studies. In Complementary Research Methods for Educational Leadership and Policy Studies (pp. 19-32). Palgrave Macmillan. https://doi.org/10.1007/978-3-319-93539-3_2

[10] Bryman, A. (2017). Quantitative and qualitative research: further reflections on their integration. In Mixing methods: Qualitative and quantitative research (pp. 57-78). Routledge. https://doi.org/10.4324/9781315248813-3 
[11] Harrison, H., Birks, M., Franklin, R., \& Mills, J. (2017, January). Case study research: Foundations and methodological orientations. In Forum Qualitative Sozialforschung/Forum: Qualitative Social Research, 18 (1). http://nbn-resolving.de/urn:nbn:de:0114-fqs1701195

[12] Renz, S. M., Carrington, J. M., \& Badger, T. A. (2018). Two strategies for qualitative content analysis: An intramethod approach to triangulation. Qualitative Health Research, 28 (5), 824-831. https://doi.org/10.1177/1049732317753586
[13] Tondeur, J., Van Braak, J., Ertmer, P. A., \& Ottenbreit-Leftwich, A. (2017). Understanding the relationship between teachers' pedagogical beliefs and technology use in education: a systematic review of qualitative evidence. Educational Technology Research and Development, 65 (3), 555-575. https://doi.org/10.1007/s11423-016-9481-2

[14] Queirós, A., Faria, D., \& Almeida, F. (2017). Strengths and limitations of qualitative and quantitative research methods. European Journal of Education Studies, 3 (9). https://doi.org/10.46827/ejes.v0i0.1017 